\title{
A regional technique for the study of sensitivity to curare in human muscle
}

\author{
J. C. BROWN ${ }^{1}$, J. E. CHARLTON, AND D. J. K. WHITE \\ From the Departments of Anaesthesia and Neurology, Royal Victoria Infirmary, \\ Newcastle Upon Tyne
}

SYNOPSIS A regional technique for the study of curare sensitivity of human muscle in vivo is described. $0.5 \mathrm{mg}$ d-tubocurarine is given intravenously at the wrist while the circulation to the hand and forearm is occluded. Neuromuscular transmission is then studied by delivering trains of stimuli to the ulnar nerve and recording changes in evoked muscle action potential (MAP) amplitude from the abductor digiti minimi. In most normal subjects, this dose causes a recognizable block in neuromuscular transmission. The amplitude of a single evoked MAP is depressed and declines further during trains of $3 / \mathrm{s}$ repetitive stimulation. Recovery usually takes place gradually during the 20-30 minutes after the release of the tourniquet. The technique will be of value in the study of latent disturbance of neuromuscular transmission in neurological and metabolic disorders.

Undue sensitivity to curare indicates altered neuromuscular transmission. This has been most intensively studied in myasthenia gravis (Rowland et al., 1961). Excessive sensitivity can exist in other disorders: amyotrophic lateral sclerosis (Mulder et al., 1959), rheumatoid arthritis (Oosterhuis and de Haas, 1969), and ocular myopathy (Ross, 1963; Mathew et al., 1970) are among the conditions in which curare sensitivity has been reported, sometimes in the absence of previous muscular weakness or fatigue, while antibiotics may also increase curare sensitivity (Pittinger and Adamson, 1972).

Thus, the functional reserve of the neuromuscular junction may allow a latent defect of neuromuscular transmission to exist without evidence of any clinical disorder. Curare-like drugs overcome this reserve and reveal such latent defects. Hence, more sensitive studies of neuromuscular transmission can be performed. Such studies have not previously been feasible on a large scale since this would involve the intravenous administration of 'near-curarizing' doses to ill patients. Not only would this be dangerous but objective measurements of their effect can be difficult to interpret.

1 Present address: Norfolk and Norwich Hospital, Norwich, Norfolk, NOR 3SR.
A regional technique overcomes these difficulties. A reduced dose of curare may be injected into a limb rendered ischaemic and its effect on muscular strength in that limb subse quently studied. Foldes et al. (1968) recorded changes in grip strength, while Feldman and Tyrrell (1970) recorded the force of evoked muscle contraction, induced by curare given while the forearm circulation was occluded by a tourniquet above the elbow. The present study describes the effect of curare upon neuromuscular transmission by recording changes in the amplitude of the muscle action potential (MAP) evoked by trains of supramaximal electrical nerve stimuli in the upper limb. Variations in technique were tried, leading to the method eventually adopted. These, and the results in normal subjects, are outlined in this paper and the results in pathological states in subsequent papers.

\section{METHODS}

There were 22 subjects of both sexes aged between 28 and 76 years: they comprised medical staff and patients with no evidence of systemic illness or of neurological disturbance in the arm studied. No patients were receiving medication at the time of the 


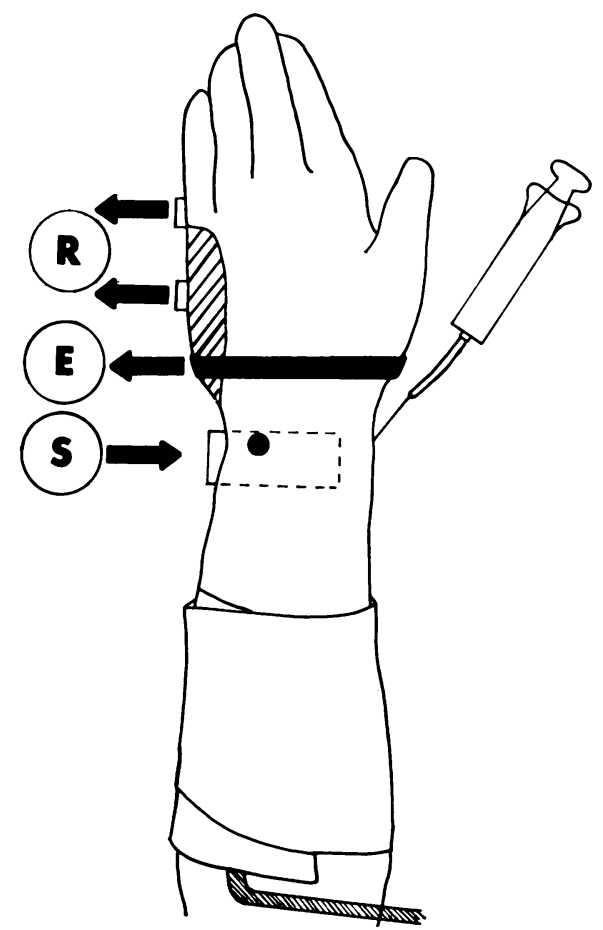

study. All studies were carried out with the subjects lying on a bed.

STIMULATION Supramaximal stimuli of $0.2 \mathrm{~ms}$ duration were delivered to the ulnar nerve at the wrist through surface electrodes from a Devices stimulator (type 3072) triggered by a Digitimer through a gated pulse generator. The anode, a $5 \mathrm{~cm} \times 1 \mathrm{~cm}$ silver strip coated with silver chloride was placed across the back of the wrist. The cathode (stimulating electrode) was a silver rod with a rounded silver chloride coated tip $3 \mathrm{~mm}$ in diameter. Its optimal site (at which the smallest current evoked the entire MAP response) was located. Both electrodes were then firmly fixed to a frame encircling the wrist to prevent any alteration in their position. Throughout the studies, the stimulus intensity used was $150 \%$ of that required to evoke the entire MAP response.

RECORDING The MAP was recorded between silver disc surface electrodes of $1 \mathrm{~cm}$ diameter, one over

FIG. 1. Positions of recording (R), earthing (E), and stimulating (S) electrodes and site of injection and tourniquet to occlude distal $720 \mathrm{ml}$ of limb.

TABLE

'REGIONAL' CURARE-SENSITIVITY IN NORMAL SUBJECTS (MUSCLE ACTION POTENTIAL EXPRESSED AS $\%$ OF PRE-CURARE AMPLITUDE)

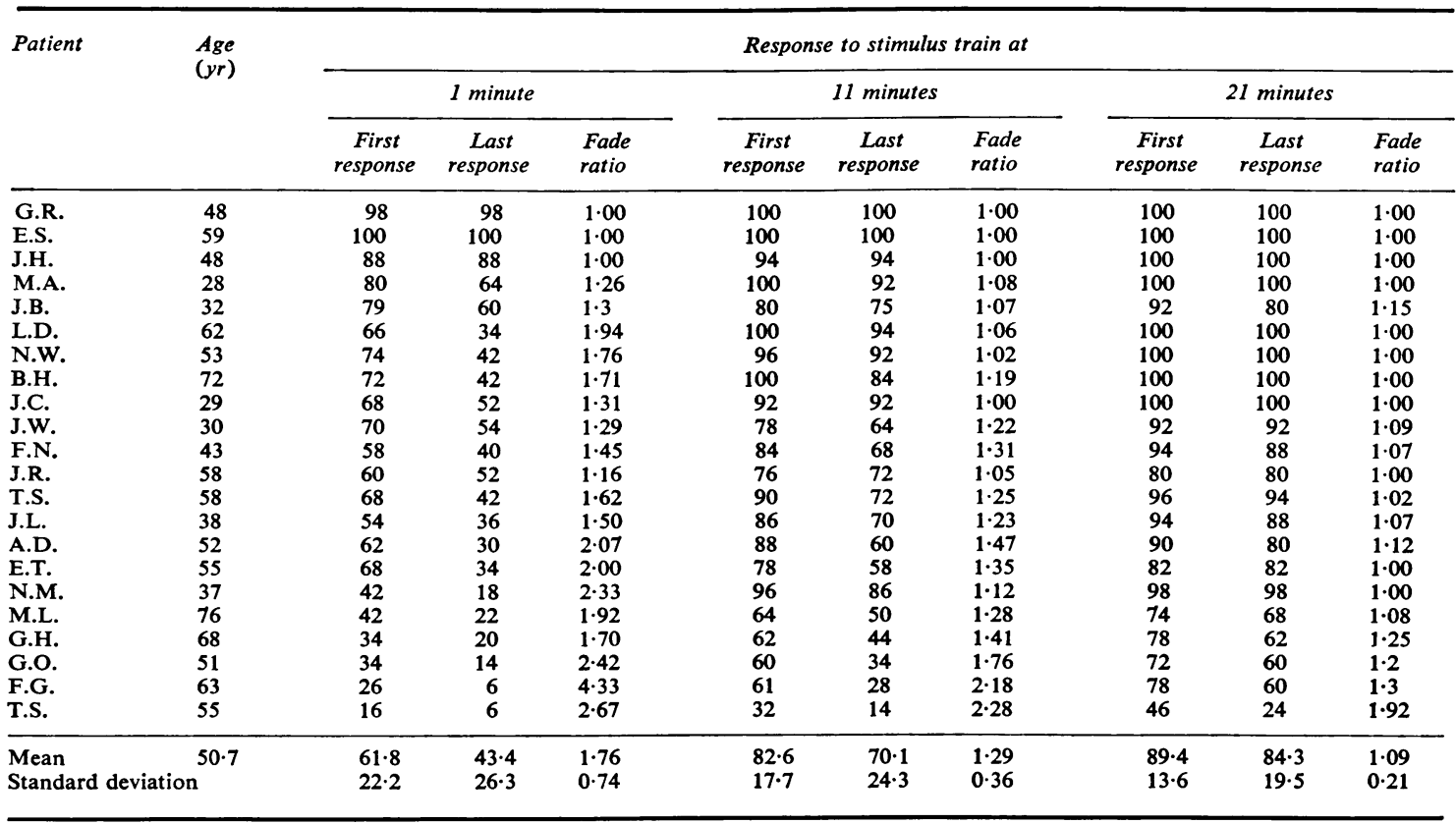




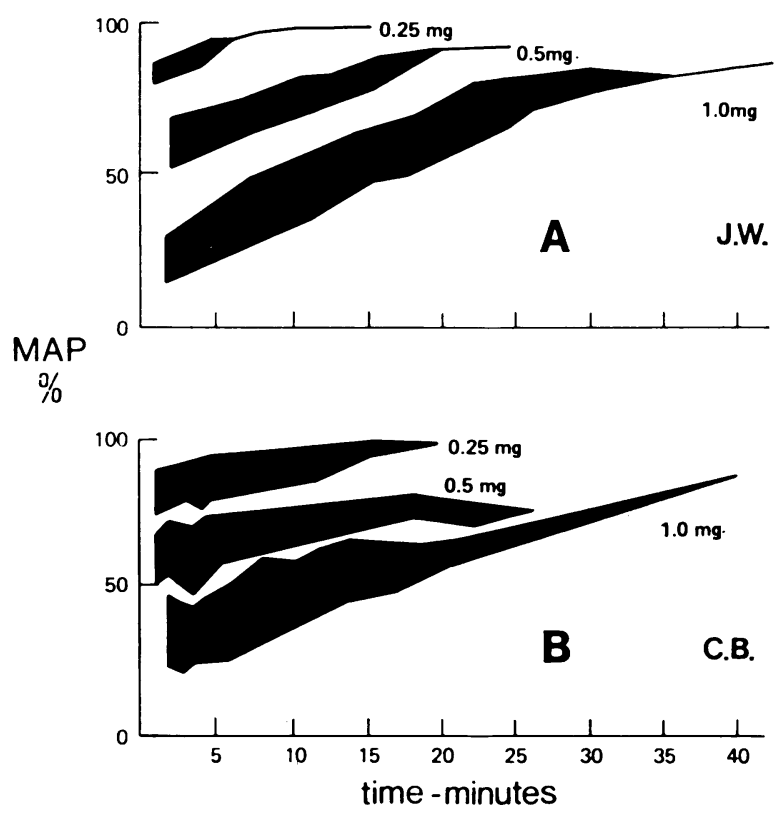

FIG. 2. Effect of different doses of d-tubocurarine in two normal subjects: the amplitude of the evoked MAP, expressed as a percentage of that obtained before the injection is plotted against the time after release of the tourniquet. The upper margin represents the first and the lower margin the last MAP evoked by. each stimulus train (see text).

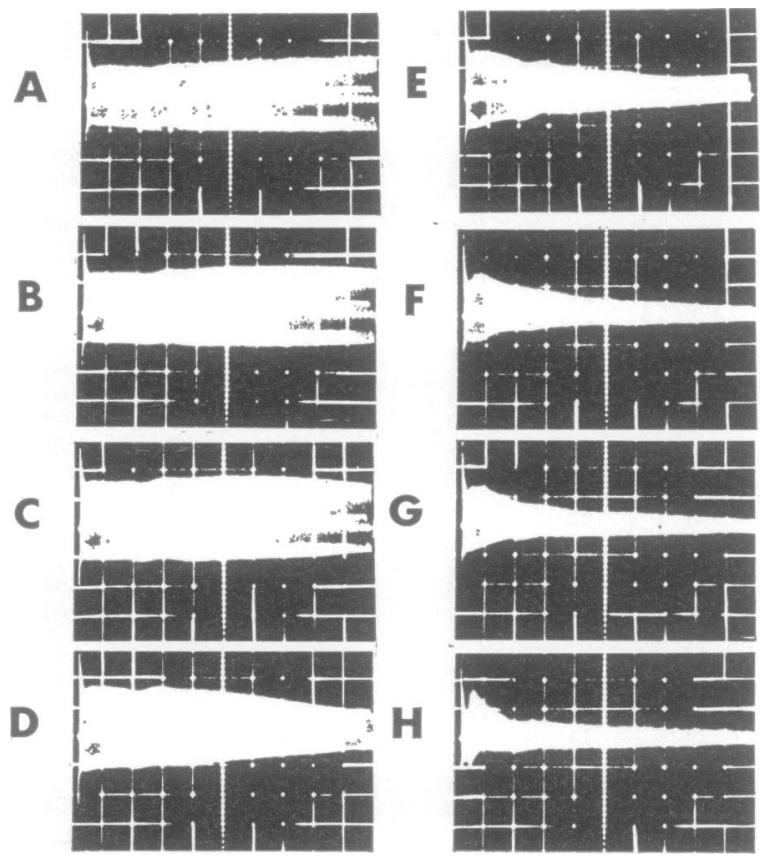

FIG. 3. MAP evoked by 10 second trains of supramaximal nerve stimulation in a normal subject at $\mathrm{A} 30, \mathrm{~B} 40, \mathrm{C} 50, \mathrm{D} 60, \mathrm{R} 70, \mathrm{~F} 80$, $\mathrm{G} 90$, and $\mathrm{H} 100$ per second after the "regional" injection of $0.5 \mathrm{mg} d$-tubocurarine. Vertical divisions $2 \mathrm{mV}$; horizontal divisions, one second. 
the belly of the abductor digiti minimi and the other at the base of the fifth finger. Responses were amplified by a parametric amplifier (Medelec type 2A3) and displayed on a storage oscilloscope (Tektronix type 564B). Earthing was affected by an electrode encircling the wrist distal to the stimulating electrodes. Isometric contraction was ensured by mechanical fixation of the hand to a board.

INJECTION, SITE, AND PLACEMENT OF TOURNIQUET Initially, the curare (d-tubocurarine) was injected intravenously in the cubital fossa, the circulation being occluded by sphygmomanometer cuff inflated above systolic pressure above the elbow. However, erratic results were obtained, related presumably to the variable retrograde diffusion of the d-tubocurarine down the length of the forearm to the receptor site in the hand.

For this reason, the injection was made through a butterfly needle ( $21 \mathrm{G}$ intermittent reseal, Abbott) inserted into a superficial vein at the lateral aspect of the wrist over the radial styloid at an almost constant site. With the sphygmomanometer cuff round the forearm (Fig. 1), in the normal adult, the volume of limb distal to the cuff was found by water displacement to be $720 \mathrm{ml}$. This volume was therefore used in subsequent studies so that, under the same condition of injection, there was a constant relationship between the dose and the volume of limb, surface area (and, hence, volume) being more closely related to curare effect than weight (Cotev and Robin, 1969).

It was first established that, without occlusion of the circulation, up to $15 \mathrm{mg}$ d-tubocurarine had no recognizable effect upon MAP amplitude in the hand. However, the injection of as little as $0.25 \mathrm{mg}$ into the occluded limb resulted in reproducible alterations in evoked MAP amplitude still evident after the release of the cuff. The dose ultimately selected $(0.5 \mathrm{mg})$ induced such changes in two out of 22 normal subjects.

The problem of inadequate perfusion after a small volume injection was overcome by first diluting the d-tubocurarine in $20 \mathrm{ml}$ normal saline. During the injection, the transient tingling sensation and blanching of skin revealed the extent of retrograde diffusion. The study is further facilitated by the local anaesthetic effect; the electrical stimulus feels less intense and is more easy for the patient to tolerate. Furthermore, the lowered motor nerve threshold stimulation induced by the curare ensures that the stimulus remains supramaximal.

PROCEDURE ULTIMATELY USED After determining the site for positioning the sphygmomanometer cuff by water displacement, stimulating and recording electrodes were applied and the needle with cannula inserted at the wrist and kept open with saline. The ambient temperature was maintained at $20-22^{\circ} \mathrm{C}$. A MAP was evoked by a supramaximal nerve stimulus and its peak to peak amplitude noted. The amplifier calibration was then adjusted so that this amplitude was five calibration divisions on the oscilloscope, enabling subsequent potentials to be more easily compared with the initial response.

The arm (with electrodes attached) was raised vertically for 30 seconds after which the cuff was inflated. The arm was laid down once more and the

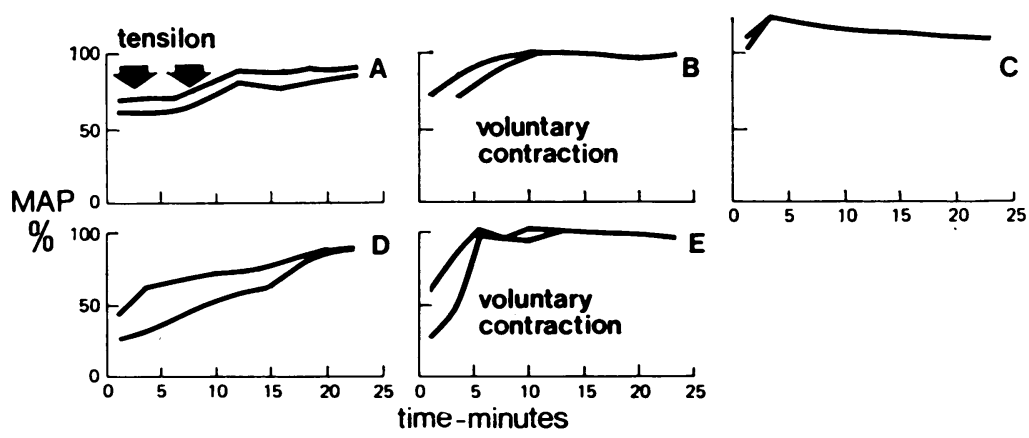

FIG. 4. Effect of (A) edrophonium (Tensilon) $10 \mathrm{mg}$ intravenously, and (B), voluntary muscle contraction upon the recovery of the MAP after the 'regional' injection of $0.5 \mathrm{mg}$ d-tubocurarine in a normal subject. Supramaximal nerve stimulation at 10 per second during this injection $(C)$ prevents the normal effect of d-tubocurarine. The more rapid recovery during voluntary muscle contraction is also shown in a second normal subject (E) compared with recovery during rest $(\mathrm{D})$. 
injection made over 60 seconds. Thereafter, a further $5 \mathrm{ml}$ saline were given to flush this through. Ischaemia was maintained for a further $4 \frac{1}{2}$ minutes. After release of the cuff, a further minute was allowed before neuromuscular stimulation was commenced.

Three-second trains of stimuli were delivered to the nerve at a frequency of $3 / \mathrm{s}$ and the peak-to-peak amplitude of the greatest (first) and smallest (last) MAP measured. These were expressed as a percentage of the initial amplitude. When plotted against time, they show the recovery of neuromuscular function as the curare effect recedes (Fig. 2). The first response is divided by the last response to each stimulus train to give a numerical value for the decrease in MAP amplitude during the train. This we have termed the fade ratio (Table).

PRECAUTIONS An anaesthetist with facilities for assisted ventilation was present during every study. The strength of d-tubocurarine used, $0.5 \mathrm{mg}$, is about $1 / 60$ th of the normal adult 'curarizing dose'. This would seem to leave a more than adequate safety margin. However, Rowland et al. (1961) reported respiratory arrest in a patient with myasthenia gravis after the administration of $0.125 \mathrm{mg}$ and we do not consider that this investigation would be justifiable without these precautions.

Doses above $0.5 \mathrm{mg}$ (up to $15 \mathrm{mg}$ ) were used only in three medical staff volunteers in whom the same precautions were taken.

\section{RESULTS}

We confirmed that neither during ischaemia for up to 20 minutes nor in the post-ischaemic state were there any changes in the amplitude of the evoked MAP. Next, it was shown that the injection of $20 \mathrm{ml}$ normal saline under the conditions of the study did not affect the evoked MAP. The effect of different doses of curare, the studies being performed on separate days, in two subjects is shown in Fig. 2. It can be seen that both the intensity of the block and its duration are closely related to the dose. Confirmation of the diffusion of the injection throughout the isolated limb was obtained through radioactive uptake studies. $400 \mu \mathrm{Ci}$ of $113 \mathrm{mIn}$ transferrin in $20 \mathrm{ml}$ saline was injected at the same site under identical conditions. Rectilinear scanning after three minutes showed a diffuse uptake throughout the hand.

EFFECT OF RAPID STIMULUS FREQUENCIES In one subject, 10 second trains of stimuli from 20 to $100 / \mathrm{s}$ were delivered to the nerve at between one minute and 10 minutes after the release of the cuff after the injection of $0.5 \mathrm{mg}$ d-tubocurarine

time-minutes

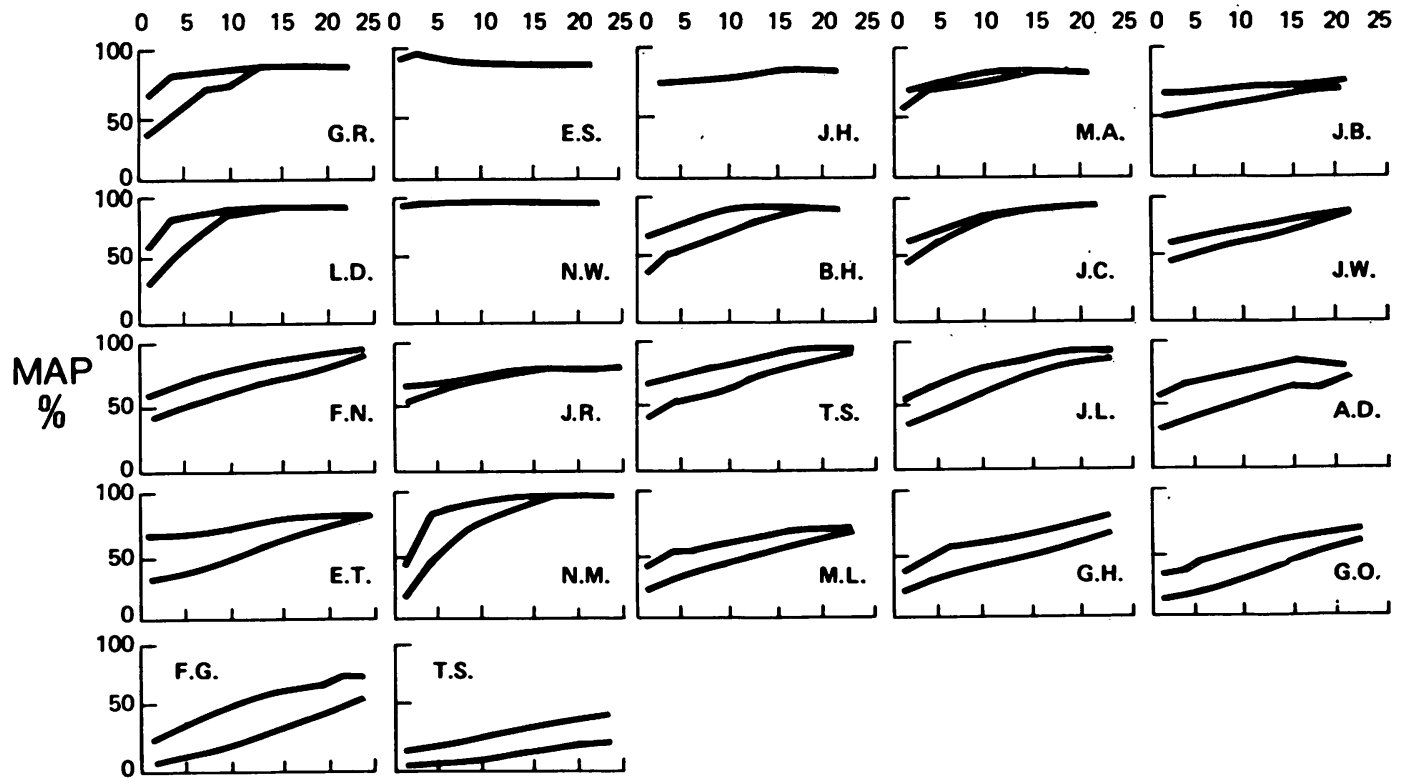

FIG. 5. Effect of 'regional' injection of $0.5 \mathrm{mg}$ d-tubocurarine in 22 normal subjects (see text). 
(Fig. 3). At each frequency, an initial rapid decline in amplitude is followed by a moderate increment which, at frequencies above 30 per second, gives way to a further late decline, more prominent as the frequency increases. This response is similar to that seen in myasthenia gravis (Johns et al., 1955). However, the initial decline at rapid rates is less marked than at $3 / \mathrm{s}$, indicating that the neuromuscular transmission block is best shown in this technique at slow frequencies.

EFFECT OF VOLUNTARY MUSCULAR CONTRACTION AND REPETITIVE STIMULATION UPON RESPONSE AMPLITUDE In two subjects the study was repeated with voluntary isometric contraction of the abductor digiti minimi maintained for the first five minutes after the release of the cuff. While the initial depression of MAP was greater, a more rapid recovery took place (Fig. 4).

In one subject, the study was repeated with repetitive ulnar nerve stimulation at 10 per second throughout the injection and for the five minute period of ischaemia. After release of the cuff there was no decline in MAP amplitude as compared with the pre-injection recording. A decline had occurred in this subject when the study has been performed without such stimulation.

EFFECT OF 3/S STIMULUS TRAINS USED IN THIS STUDY UPON RECOVERY OF MAP AMPLITUDE In one subject the study was repeated with stimulus trains delivered only at one, 11 , and 21 minutes after the release of the cuff. There was a slower rise in MAP amplitude than in the study performed on the same subject using the standard technique of delivering such trains every two minutes. In addition, decremental response during the stimulus trains persisted. Thus, the nerve stimulus trains delivered during these studies facilitate the recovery of MAP amplitude.

EFFECT OF TEMPERATURE In two subjects studies were repeated with the arm cooled until the surface temperature of the hand had fallen to 32 $34^{\circ} \mathrm{C}$ (by encasing it in a container of crushed ice) and warmed to $40^{\circ} \mathrm{C}$, and the results compared. In one, the decline in amplitude during the trains was slightly greater in the warmed limb, and in the other the overall depression of MAP amplitude was slightly greater in the warmed limb. These changes however were so slight as to appear within the range of normal variation for the study.

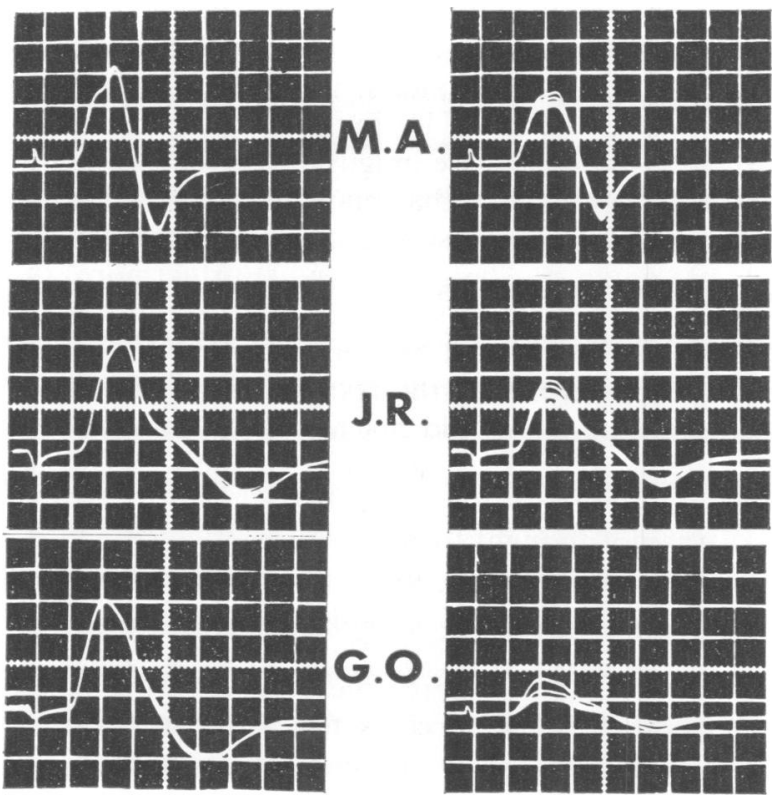

FIG. 6. Examples of differing curare-sensitivity in three of the subjects studied. Recordings of superimposed muscle action potentials evoked by the stimulus train. In each, on the left, before the injection. On the right one minute after the release of the tourniquet after $0.5 \mathrm{mg}$ d-tubocurarine. Vertical divisions, $2 \mathrm{mV}$. Horizontal divisions, $2 \mathrm{~ms}$. 
EFFECT OF EDROPHONIUM In one subject the study was repeated with $10 \mathrm{mg}$ edrophonium (Tensilon) being given between the fifth and seventh minute after the release of the cuff, into the contralateral arm. For the five minutes after the start of this injection there was a somewhat more rapid growth of MAP amplitude (Fig. 4).

RESULTS IN NORMAL SUBJECTS The results of the study in the first 22 subjects are shown in Fig. 5 and in the Table. In all but two there was a recognizable fall in MAP amplitude and a fade during $3 / \mathrm{s}$ stimulation in all but three. However, the extent of this fall, the degree of fade, and the time taken to recover showed considerable variation from subject to subject. By and large, the greater the fall in MAP amplitude, the longer it took to recover. Indeed, in some cases this had still not recovered after 30 minutes. Reproducible results were obtained when the study was performed on separate days in the same subject.

\section{DISCUSSION}

Not enough is understood of the finer effects of the central nervous system or metabolic disturbance upon the neuromuscular junction. Only where such disorders are great enough to cause a functional block of neuromuscular transmission can changes be clearly recognized using conventional neuromuscular stimulation techniques. This and subsequent papers will show that the competitive blocking action of d-tubocurarine can be utilized in a regional technique to reveal latent changes in neuromuscular transmission.

The variation in the response of different normal subjects shown here (Fig. 6) indicates that the technique has limitations. It is not possible to control the concentration of d-tubocurarine at the relevant neuromuscular junction, largely due to the differences in vasculature and perfusion. The effect of d-tubocurarine in the tissues will depend on the concentration and volume administered, the amount of exsanguination caused by elevating the limb, and the state of the vascular bed. Despite this, a normal range of curare sensitivity can be defined. The technique will be of value if it can demonstrate that results outside this range occur in subclinical disorders of neuromuscular transmission and if the response in pathological states is significantly different. Both these points will be shown.

By blocking a proportion of the receptor sites at the neuromuscular junction, d-tubocurarine reduces the number of muscle fibres able to respond to the supramaximal nerve stimulus. Paton and Waud (1967) have estimated that over $70 \%$ receptor occupancy is necessary for a decline of twitch height and somewhat less for an effect on the MAP. The extent of the block will depend on the concentration of d-tubocurarine at the junction, the state of the post-junctional membrane, and the concentration of acetylcholine released from the nerve ending. Other factors which can affect the extent of the block are temperature, $\mathrm{pH}$, and plasma protein concentration. The action of curare is antagonized by cooling (Cannard and Zaimis, 1959) and there may be a slower rate of production and release of acetylcholine at lower temperatures (Katz and Miledi, 1965). The changes found in the response to d-tubocurarine with variation in the temperature of the isolated limb were so slight as to appear within the range of normal variation for the study. It is possible that any alteration due to difference in temperature may in part be mediated through changes in capillary perfusion affecting the distribution of the d-tubocurarine.

The action of d-tubocurarine is prolonged, and the depth of the block intensified by acidosis (Gamstorp and Vinnars, 1961). This could have been counteracted by buffered solutions. However, though these might maintain the extracellular $\mathrm{pH}$, the ischaemia would alter cell membrane diffusibility so that control of intracellular pH could not be guaranteed. Furthermore, the acidosis caused by ischaemia is a constant feature in each study and can probably be discounted when interpreting the results, particularly since ischaemia alone did not affect the amplitude of the evoked MAP. In similar studies (Foldes et al., 1968; Feldman and Tyrrell, 1970) acidosis was not thought to be a source of error.

Plasma protein levels affect the binding of muscle relaxants (Aladjemoff et al., 1958; Stovner et al., 1971). For this reason, plasma protein levels were measured during these studies and in all cases fell within the normal range. There was no evidence either of any 
electrolyte disturbance which might alter curare sensitivity (McKie, 1969).

There is controversy as to whether d-tubocurarine has any prejunctional activity as suggested by Galindo (1971). If so, it is likely to be very small (Auerbach and Betz, 1971). It is reasonable to assume that d-tubocurarine has its effect at the post-synaptic membrane and that its action is terminated by that of acetylcholine. The extreme sensitivity to curare-like drugs in syndromes where acetylcholine release is defective (Lambert et al., 1965) would appear to support this. Furthermore, the block could be prevented in the current study by repetitive nerve stimulation during the injection, raising the acetylcholine concentration at the end-plate region at the critical time.

The rate of recovery from the block in this technique will depend initially on the 'washout' of d-tubocurarine once the circulation in the hand is restored. This would be in accordance with the 'rate theory' of Paton (1961). However, other factors are involved, in particular the concentration of acetylcholine at the neuromuscular junction. In this study, the administration of the anticholinesterase edrophonium, voluntary muscle contraction, or repetitive nerve stimulation each facilitated recovery of the amplitude of the MAP. This is in keeping with the findings of Feldman and Tyrell (1970). Delay in recovery might be an indication of reduced availability of acetylcholine or of 'binding' of the relaxant at the receptor site.

The changes induced by d-tubocurarine on the abductor digiti minimi muscle in this study may not be comparable with other muscles. The magnitude of the block induced depends upon which muscle is tested (Katz, 1973). Furthermore, different results may be obtained if mechanical rather than electrical responses are measured. However, the technique described here has yielded reproducible results and its value in the study of latent neuromuscular transmission disorders will become evident in subsequent papers.

We wish to thank Mr P. Smith for technical assistance, Miss M. Stevenson for secretarial assistance, and Mr E. Stanley for help with statistical analysis. We are grateful to Dr F. R. Ellis and Dr D. J. Aidley for helpful advice and to Dr D. A. Shaw for per- mission to study his patients. The work was supported by Grant 17912 from the Medical Research Council.

\section{REFERENCES}

Aladjemoff, L., Dikstein, S., and Shafrir, E. (1958). The binding of $d$-tubocurarine chloride to plasma proteins. Journal of Pharmacology and Experimental Therapeutics, 123, 43-47.

Auerbach, A., and Betz, W. (1971). Does curare affect transmitter release? Journal of Physiology, 213, 691-705.

Cannard, T. H., and Zaimis, E. (1959). The effect of lowered muscle temperature on the action of neuromuscular blocking drugs in man. Journal of Physiology, 149, 112-119.

Cotev, S., and Robin, G. C. (1969). Experimental studies on intravenous regional analgesia using radioactive lidocaine. Acta Anaesthesiologica Scandinavica, Suppl. 36, 126-130.

Feldman, S. A., and Tyrrell, M. F. (1970). A new theory of the termination of action of the muscle relaxants. Proceedings of the Royal Society of Medicine, 63, 692-695.

Foldes, F. F., Klonymus, D. H., Maisel, W., and Osserman, K. E. (1968). A new curare test for the diagnosis of myasthenia gravis. Journal of the American Medical Association, 203, 649-653.

Galindo, A. (1971). Prejunctional effect of curare: its relative importance. Journal of Neurophysiology, 34, 289-301.

Gamstorp, I., and Vinnars, E. (1961). Studies in neuromuscular transmission. 1. Influence on neuromuscular transmission of alkalosis and acidosis. Acta Physiologica Scandinavica, 53, 142-150.

Johns, R. J., Grob, D., and Harvey, A. M. (1955). Electromyographic changes in myasthenia gravis. American Journal of Medicine, 19, 679-683.

Katz, B., and Miledi, R. (1965). The effect of temperature on the synaptic delay at the neuromuscular junction. Journal of Physiology, 181, 656-670.

Katz, R. L. (1973). Electromyographic and mechanical effects of suxamethonium and tubocurarine on twitch, tetanic and post-tetanic responses. British Journal of Anaesthesia, 45, 849-859.

Lambert, E. H., Okihiro, M., and Rooke, E. D. (1965). Clinical physiology of the neuromuscular junction. In Muscle, pp. 487-499. Edited by W. M. Paul, E. E. Daniel, C. M. Kay, and G. Monckton. Pergamon Press: Oxford.

McKie, B. D. (1969). Hypocalcaemia and prolonged curarization. A case report. British Journal of Anaesthesia, 41, 10911094.

Mathew, N. T., Jacob, J. C., and Chandy, J. (1970). Familial ocular myopathy with curare sensitivity. Archives of Neurology, 22, 68-74.

Mulder, D. W., Lambert, E. H., and Eaton, L. M. (1959). Myasthenic syndrome in patients with amyotrophic lateral sclerosis. Neurology (Minneap.), 9, 627-631.

Oosterhuis, H. J. G. H., and Haas, W. H. D. de (1969). Curare sensitivity and myastheniform symptoms in patients with rheumatoid arthritis. Acta Rheumatologica Scandinavica, 15, 54-61.

Paton, W. D. M. (1961). A theory of drug action based on the rate of drug-receptor combination. Proceedings of the Royal Society, B, 154, 21-69.

Paton, W. D. M., and Waud, D. R. (1967). The margin of safety of neuromuscular transmission. Journal of Physiology, 191, 59-90.

Pittinger, C., and Adamson, R. (1972). Antibiotic blockade 
of neuromuscular function. Annual Review of Pharmacology, 12, 169-184.

Ross, R. T. (1963). Ocular myopathy sensitive to curare. Brain, 86, 67-74.

Rowland, L. P., Aranow, H., Jr, and Hoefer, P. F. A. (1961).

Observations on the curare test in the differential diagnosis of myasthenia gravis. In Myasthenia Gravis, pp. 411-434. Edited by H. R. Viets. Thomas: Springfield, Ill.

Stovner, J., Theodorsen, L., and Bjelke, E. (1971). Sensitivity to tubocurarine and alcuronium with special reference to plasma protein pattern. British Journal of Anaesthesia, 43, 385-391.

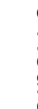

. 